\title{
Introduction: the expanding frontiers of economics and nonprofit management research - revisited
}

\author{
Bruce A. Seaman and Dennis R. Young
}

This second edition updates (from 2010), and in some cases substantially modifies, the first edition's 22 chapters, incorporating new research published or distributed as recently as 2017. As with the first edition, the chapters here are written by leading scholars in the economics and management of nonprofit organizations. We have added two entirely new chapters: 'The social economy: an international comparison' (Chapter 22) and 'Nonprofit organizations and the macroeconomy' (Chapter 23). We did not update or include one chapter ('Certification and self-regulation of nonprofits, and the institutional choice between them'), but continue to view that material as important for nonprofit scholars and refer readers to the original edition (Chapter 19 by Andreas Ortmann and Jan Myslivecek). Of the 21 original chapters that were modified, six include some change to the chapter title. The contents continue to focus on three broad areas of nonprofit research - nonprofit finance including income generation and asset and expense management; the engagement of nonprofits in markets, including labor markets, competition and collaboration in product and service markets, and mixed markets that include both nonprofit and for-profit providers; and nonprofit-related public policy issues including federal and state or local tax policy, policy relating to competition and collaboration, policy affecting economic growth and policy-related performance assessment. This second edition extends the scope of the handbook by its additional attention to the macroeconomy, alternative methodological approaches and international contexts. The contributions of experimental research methods, and the insights of behavioral economics and psychology, are discussed in a number of chapters, and those approaches continue to expand into nonprofit research as they have so widely throughout economics and the social sciences. The fact that we have been encouraged to develop this second edition less than a decade after the first, speaks to the rapid expansion and diversification of the fields of nonprofit economics and management research. While chapters in the first edition have remained relevant over time, we have been impressed with how much more has been studied in the years since 2010 and how important it is to periodically review and refresh this growing knowledge base in light of the dynamic environments in which nonprofits continue to operate.

The first edition has been widely used in graduate nonprofit management, finance and economics courses, and the second edition continues the framing of chapter discussions around the current state of research knowledge on the various topics under scrutiny, specifically addressing four dimensions of interest: (1) areas of general agreement from existing research; (2) conflicting results and unexplored questions; (3) the relative roles of theory, data availability and empirical analysis in explaining gaps in our knowledge; and (4) what must be done to improve our knowledge and extend the literature. Although the chapters rely on critical reviews of the relevant literatures, including the most recent 
contributions, some chapters include original research results of their own. While the audience for this book remains primarily fellow researchers, especially young scholars in the process of shaping their own research agendas, great care has also been taken to address the concerns of practicing nonprofit sector managers and leaders, policy-makers and community decision-makers. We would like to acknowledge the efforts of Erin Vokes and Stuart Mendel in organizing the 'Wise Economic Decision Making' meeting on 17 March 2017 in Cleveland, which provided the opportunity for many of our authors to compare notes, talk with nonprofit and other community leaders, and provide guidance to each other for revising their chapters or writing new ones. This event, hosted by the Maxine Goodman Levin College of Urban Affairs at Cleveland State University, was produced in partnership with Edward Elgar Publishing, the National Center on Nonprofit Enterprise and Business Volunteers Unlimited, and financially supported by United Way of Cleveland, Richard W. Pogue, Buckingham, Doolittle \& Burroughs, The Center for Nonprofit Policy \& Practice of Cleveland State University, Mario Morino and the Nonprofit Academic Centers Council. We also wish to thank our executive editor, Alan Sturmer, for his steadfast support of this handbook and his encouragement to produce a second edition. We are grateful for the support of these partners and sponsors, to the community leaders who participated in the meeting, and to the outstanding group of nonprofit scholars who came together to produce this volume.

The observations and reactions of community leaders to the discussions with and among the authors highlighted at least four challenges facing academic researchers on nonprofit issues, and facing researchers in most fields: (1) how to provide timely and coherent advice to decision-makers based on research that can be contradictory, and that incorporates results using data, theoretical developments and institutional considerations that can extend over lengthy time periods; (2) how to cope with the perpetual dilemma of data quality, including the challenges of using data generated for administrative purposes and not intended for rigorous testing of research hypotheses; (3) how to incorporate the insights of a growing and demanding methodological literature on the challenges of replicating empirical research results, the 'tyranny' of statistical significance in contrast to economic (or more generally 'causal' significance) in evaluating econometric findings, and gnawing concerns about what can really be known about social issues and behavioral regularities of complex organizations; ${ }^{1}$ and (4) how to enhance productive communications and problem-solving between academic researchers and nonprofit sector and community decision-makers, with each of these groups facing different constraints, incentives, peergroup pressures, and obligations to answer to different constituencies - factors that easily create misunderstandings and conflicting agendas when researchers try to share their 'findings' with practitioners. By giving voice to these concerns, we hope that this volume can help sensitize current and future researchers to take them into account in formulating their research designs and dissemination strategies.

Because political developments can change the constraints affecting nonprofit managers stemming from budgetary support, regulatory policies, tax structures and the magnitude of particular social problems often addressed by nonprofit organizations, authors were encouraged to consider where recent political changes in the US and elsewhere might affect the issues they were addressing. Not all chapters address policy issues and managerial challenges that are likely to be affected by political volatility, but selected authors did attempt to provide informed commentary on such developments. 
The 43 contributors to the second edition include 17 entirely new authors, along with 22 returning active authors. Two of those returning active authors assumed different roles: James Alm moved from authoring the first edition Foreword to co-authoring (with new author Daniel Teles) Chapter 19 on state and federal tax policy, while Laurie Mook extended her co-authorship role with Femida Handy in Chapter 18 ('Social accounting for value creation') to also include Chapter 22 (with new author Jack Quarter) on 'The social economy: an international comparison'. Two first edition authors (Cyril Chang and Richard Sansing) had assumed demanding administrative positions that prevented their active involvement, but the new authors of their respective (renamed) chapters on income diversification (Grace L. Chikoto-Schultz), and distribution policies of private foundations (Patrick Rooney and Jon Bergdoll) built upon and notably extended those earlier contributions. We have dedicated this second edition to the late Howard Tuckman (included as a co-author of Chapter 1 with Cyril Chang and Grace L. Chikoto-Schultz), and the late Woods Bowman, whose first edition chapter on asset composition was constructively extended and updated by new authors Thad Calabrese and Elizabeth Searing (Chapter 5).

We are delighted that Lester Salamon has contributed the Foreword to this second edition, offering his unique perspective as a seminal contributor to the field of nonprofit research, especially in the areas of public policy, international comparative work and theory of the nonprofit sector. Among his many valuable observations, he challenges the field of economics to recognize the limitations of its central paradigmatic assumption of rational actors free to choose among various alternatives, always with the goal of making the most efficient use of resources in order to maximize profits, and praises this volume for at least demonstrating some humility in recognizing the limitations of economic analysis in accounting for the actual behavior of nonprofit organizations. We accept those criticisms, and appreciate Salamon's suggestion that in pointing out the limitations of standard economic analysis to account for nonprofit operations, this volume can help show the way towards a new economics not only to adequately address the nonprofit sector, but to take account of broader societal developments as well. We also continue to be impressed by the capacity of economic analysis to adapt (even if at times very slowly) to the challenges of generating relevant policy-orientated and managerially useful research by imposing genuine discipline on researchers via its focus on testable theory, the rigorous generation of hypotheses, and a determination to ask hard questions about the logical consistency of various postulated behaviors and strategies. Arguably, economics continues to be the core social science and business discipline, with its insights and methods influencing many other fields of study. As with all disciplines, adapting to legitimate criticism generates resistance. Nonetheless, a significant segment of economists has incorporated and built upon such criticism, ranging from Austrian challenges to static concepts of competition and equilibrium and welfare theorems, to arguments that bounded rationality, asymmetric information, transaction costs and contract failure and resulting institutional adaptations are essential for understanding firm organization and behavior (for example, see Chapter 14). Also, the more recent explosion of experimental and behavioral research has sometimes confirmed, but other times notably challenged, long held precepts, with experimental and behavioral economics becoming important subfields within the discipline. Without question, the relationship between the realities of firm or organization and individual behavior and the academic disciplines that study 
them has always been symbiotic - with real-world challenges reminding researchers how little they know about some issues, hence motivating them to renew their efforts to generate more relevant and insightful analysis. In turn those new academic insights have the potential to enhance actual decision-making and policy generation. We are pleased that as astute an analyst as Lester Salamon finds this book's efforts to 'test the applicability of economic concepts to the world of nonprofit operations' (Foreword) a potentially valuable resource in determining whether a 'new economics' is required. ${ }^{2}$

While closely related, the literatures on management of nonprofit organizations and the economics of nonprofits do not entirely intersect and cross-fertilize one another. The former is an interdisciplinary collection that draws heavily on business management and public administration research, practitioner experience, sociology of organizations and other social science fields, and diverse methodologies including case studies, surveys, grounded theory and statistical testing based on a variety of behavioral theories, hypotheses and models. The latter, by contrast, is more homogeneous and specialized, focused on efficient use of scarce organizational and societal resources, and based largely on a common theoretical framework built on assumptions of rational decision-making and incorporating important insights about transactions costs in establishing and enforcing contracts and institutional arrangements designed to limit potential market failures (see Chapter 14). Theoretical model building and the coherent testing of hypotheses using appropriate econometric methods are critical components of economics research. Owing to their overlapping theoretical roots, fields such as finance and risk management (see Chapters 1, 4, 5 and 11) are often closely allied with economics, including their joint susceptibility to the highly influential insights provided by psychologists and behaviorists, often germinating from the dramatic expansion of experimental research methods.

To a substantial degree, the economics literature is also less generally accessible, requiring understanding of basic concepts such as marginal analysis and opportunity cost, the mathematics of constrained optimization and the subtleties of econometric modeling. Despite the fact that many economists interested in nonprofit organizations have made extra efforts to write for general audiences and to participate in interdisciplinary forums devoted to nonprofit issues, the full benefits of their thinking have not yet been felt in the general nonprofit management research arena, and much of their published research in academic journals remains largely inaccessible to non-specialists. At the same time, owing largely to the internal reward systems facing academicians, economists have not fully benefited from fresh perspectives on nonprofit decision-making issues that emanate from other disciplines (unless they become a key part of the economics literature itself, as with psychological and sociological influences on behavioral and experimental economics). Also, economists have largely resisted trying to incorporate the experiences of nonprofit (and other) decision-makers in practice.

The foregoing is evident with respect to many of the topics addressed in this book. Issues such as the pricing of services, competition, labor compensation, outsourcing, product diversification, asset diversification, franchising, internal organizational architecture, risk management and performance assessment are natural areas of intersection between economics and management research. In each of these areas, our authors demonstrate that general understanding from the nonprofit management research literature has not fully benefited from the thinking that economists can bring to the table. Yet they also find that economic analysis as applied to traditional areas of market activity is not sufficient 
to encompass the nuances arising in the nonprofit arena. For example, as Seaman points out in Chapter 10, pricing in the business sector rarely embraces strategies intended to advance a social mission at the sacrifice of additional profits, even if there are sometimes significant similarities in the pricing strategies of the two sectors, and as Oster explains in Chapter 13, it is the portfolio of loss-making and profitable initiatives intended to advance a social mission in a nonprofit organization that should underlie its product diversification strategy, not simply the seeking of additional profitable opportunities or the enhancing of market power through monopolistic competition. Cordes and Coventry, in Chapter 17, introduce the notion of 'mission-related benefits and costs' to adapt traditional cost-benefit analysis to the particular venue of nonprofits focused on social missions less comprehensive than society as a whole. In some contrast to these nonprofit differentials, however, Hirsch, Macpherson and Preston find in Chapter 8 through standard wage level analysis that, on average, wages in the nonprofit and for-profit sectors differ little for similar workers and jobs. Even here, though, these economists challenge the common view in the nonprofit management arena - that most nonprofit workers are necessarily paid less.

Alaimo in Chapter 12 notes that outsourcing by nonprofits is not a simple (make-orbuy) decision focused on comparing salient transaction, production and purchasing costs of in-house versus external provision, but rather must account for the more nuanced concerns of trust and identity associated with losing control over, and identifying with, the core mission. Moreover, ethical considerations in contracting, including potential conflicts of interest, raise greater concerns in the nonprofit arena than in the private economy as a whole. Similarly, Young and Faulk in Chapter 15 demonstrate that franchising in the nonprofit sector is not a straightforward matter of implementing a structure that optimizes the control of the central organization as principal over the branches or franchisees as agents, but rather one of determining who are the principals and who are the agents in the first place, and how the intended direction or directions of unilateral or mutual accountability are best imbedded into a federated structure. Indeed, these issues are exacerbated as nonprofit federated structures evolve into even more complex service, supplier and funding networks over time. Similarly, both Brown and Slivinski in Chapter 7 and Harrison and Irvin in Chapter 6 challenge the traditional notions of competition and monopoly in the economics literature by demonstrating how these issues are more nuanced and often qualitatively different in the nonprofit arena. For instance, one must appreciate the advantages and disadvantages of nonprofits in mixed industries where they compete with for-profit organizations (and more recently with new legal forms of social business) and are likely to be regulated by government. Moreover, a more nuanced view of competition in a nonprofit context requires understanding the circumstances where nonprofits are most likely to collaborate on their own, where they could be encouraged with external funding incentives to collaborate, and where the benefits of competition might outweigh those of collaboration.

Finally, rarely have the macroeconomic implications of nonprofit sector activity been considered, either by economists concerned with economic growth, inflation and stability of the economy as a whole, or by nonprofit institutions whose performance is affected by extant economic conditions and which in turn influence the performance of the economy through productivity enhancing services such as education, research and health care and the timeliness with which philanthropic and other resources are deployed 
over the business cycle. In Chapter 23, Steinberg argues that public policies that affect the size of the nonprofit sector, also affect the growth and state of the economy as a whole. This symbiotic relationship is just another instance where nonprofit research expands economics as a field of study and where economics contributes to more informed strategic management by nonprofits.

In all of these instances, our authors bring new perspectives to the decision-making arena of nonprofit management by applying economic concepts, tools and ideas, and by summarizing and extending what is known from research to date. At the same time, they are stretching the domain of the economics discipline itself by applying these principles and tools to territory that is less natural to it, though demonstrably quite fertile.

This book also encompasses a set of chapters that address topics peculiarly nonprofit in character, thus not encountered in traditional economics or business research, yet also highly amenable to economic analysis. In some of these areas the authors build on already substantial literatures, while others are more pristine, hence requiring pioneering efforts to map the territory and discern productive avenues of inquiry. The former category includes Tinkelman's and Neely's review in Chapter 2 of the phenomenon of 'crowding out' (or potentially 'crowding in') between one source of nonprofit revenue and another - for example, between government funding and charitable donations. While much work has been done on this subject, it is also true that results to date are neither definitive nor comprehensive. Interestingly, results differ considerably between econometric studies and those based on experiments, as Tinkelman and Neely discuss. In particular, experimental studies tend to show greater levels of crowd-out of charitable contributions by government funding than do econometric analyses. However, crowd-out is a complex, possibly nonlinear, phenomenon involving many different factors, such as the structure of gifts and grants, the relative magnitudes of alternative revenue streams, and different possible explanatory mechanisms including both donor behavior and managerial strategy. Moreover, crowding-out research has not fully explored all the possible combinations of income types including earned income, charitable income, investment income, in-kind and volunteer contributions, and government funding.

Similarly, substantial work has been done on the vexing issue of assessing the economic value of volunteer labor, although a full consensus on how this can or should be done continues to be elusive. Bania and Leete review this issue in Chapter 16, describing three alternative approaches - measuring opportunity value, replacement value or organizational value of volunteers, noting the challenges of each and how they apply in different circumstances. Despite the importance of volunteer labor as a resource for the nonprofit sector, relatively few organizations actually try to measure the value of such labor. Bania's and Leete's insights on how this might be rectified should prove valuable to nonprofit managers, and enlightening to economists who have not been following this debate.

Perhaps the most extensive literature peculiar to nonprofits is the modeling of their economic behavior, defined in terms of the quantity, quality and prices of their services and whom they serve, compared with for-profit organizations. In Chapter 9, Hughes and Luksetich document how economists model nonprofit behavior, contingent on the various goals they may seek to maximize, the constraints they must abide by and the nature of the markets within which they operate. While no consensus is reached on any singular model of the nonprofit firm, much has been learned to guide policy and managerial practice in broad segments of the nonprofit sector, including hospitals, day care, nursing 
homes and the arts. While Hughes and Luksetich examine nonprofits' external behaviors, Tortia and Valentinov develop the theory on their internal organization and governance in Chapter 14, based on the transactions cost literature. They add to this literature by identifying collective action as a third dimension of organizational governance, supplementing markets and hierarchy, and allowing the theory to fully accommodate nonprofit organizations. Specifically, these authors address the issue of organizational boundaries, directly relevant to the kinds of outsourcing decisions discussed by Alaimo in Chapter 12 and Toepler in Chapter 21. Their analysis leads to the insight that mission-related activity is least amenable to contracting out because it must be governed by collective action which is necessarily internal to the organization. More generally Tortia and Valentinov advance our thinking about how nonprofits can best integrate or separate their internal divisions devoted to mission-impacting versus ancillary mission-supporting work, a critical issue of nonprofit management in any substantial (multi-product) nonprofit operation.

Other chapters offer insights and guidance from research on a cluster of nonprofit financial management issues. These include the question of income diversification, as discussed by Chang, Tuckman and Chikoto-Schultz in Chapter 1, who ask about the best balance of funding from charitable, market, government, investment and in-kind sources. Considerable research has been devoted to this question in recent years, producing some evidence of a trade-off between stability and growth as income is diversified, and greater understanding of the connection between an organization's mission and the mix of sources by which it is financed. Similar insights are provided from research on charitable foundations by Rooney, Sansing and Bergdoll in Chapter 3 on how these institutions deploy their assets and spend from their corpuses of endowed funds, and how they are affected by regulatory and tax policies governing private foundations. They give particular attention to the 5 percent minimum payout rate that applies to private foundations in the US, documenting the arguments for and against increasing this rate and offering their own microsimulations of the effects of higher rates on the survival and growth or contraction of the financial corpuses of these institutions. Interestingly, there is a close connection between this analysis and Steinberg's consideration of nonprofits in the macroeconomy in Chapter 23. Specifically, Rooney, Sansing and Bergdoll find that foundations likely could accommodate a 2 percent countercyclical increase in payout rates during recessions without risking demise or major losses in the value of their assets.

Bowman, Calabrese and Searing, in Chapter 5, bring a broader focus to the management of nonprofit assets. These authors review what we know about the particular characteristics of nonprofit assets, including their degrees of liquidity and constraints on their dispensation and diversity by fields of service, and they identify broad issues of concern including cash flow management and the role assets play in managing risk. Broad strategies of asset management related to risk are discussed, including asset diversification, designation of reserve funds, and asset partitioning. The connection of asset composition to a nonprofit's business model (for generating its income) and to its social returns are also reviewed. These topics are all frontiers in nonprofit financial management research, and they intersect with other streams of research discussed in this book, especially on social accounting (Chapter 18), capital structure (Chapter 4), income diversification (Chapter 1), product diversification (Chapter 13), nonprofit performance (Chapter 17) and risk management (Chapter 11). An important lesson is that asset composition and 
management is central to nonprofit performance, and we still have much to learn about its various impacts and implications.

The issue of capital structure - the relationships (mix) between debt and equity in the balance sheets of nonprofit organizations, and the strategies nonprofits use to finance capital requirements - is addressed by Jegers in Chapter 4. Jegers argues the need for theory development on nonprofit capital structure as well as the paucity of empirical studies on this issue. For-profit theories of capital financing, including static trade-off theory and pecking order theory, adapt imperfectly to the nonprofit sector, begging further refinement. Meanwhile, practical questions such as collateralizing equity (for example, retained earnings and pledged gifts) to enable debt financing, determining the cost of capital and prioritizing debt versus equity strategies, await further insights from research. Part of the challenge is appropriate accounting practices, as discussed by Mook and Handy in Chapter 18 who offer the latest developments in the field of social accounting, taking into consideration the social as well as the market value of nonprofit assets and programs. In particular, these authors argue the efficacy of the Expanded Value Added Statement (EVAS), an advance in modern accounting practice that allows nonprofits (and other socially impactful organizations) to properly account for unpaid labor, provision of employment and skill development for their members, and contributions to society through service, employment and tax payments. This is not an exercise in idealism so much as a mechanism through which a nonprofit organization can hold itself publicly accountable and demonstrate its real value to its various stakeholders and sources of support.

As noted previously, an important component of nonprofit financial management is the management of risk. In Chapter 11, however, Grace makes clear that nonprofit risk goes well beyond financial risk, and that research and theory development on nonprofit risk management requires far more development. Grace describes a spectrum of important types of nonprofit risk including reputational, operational, financial, environmental, regulatory and strategic, which can be managed by an array of tools including technology, insurance, organizational restructuring and parsing of the kinds of activities undertaken by nonprofit organizations in the first place. Grace's case studies of the experiences of the American Red Cross and the Catholic Church offer important lessons for practice as well as motivation for broader empirical study.

In the realm of public policy affecting nonprofit organizations, several chapters reveal important insights from research and identify substantial gaps that remain in our knowledge and new frontiers for scholars to explore. Chapter 20 by Sjoquist and Stoycheva address a relatively pristine landscape of economic analysis of the implications of nonprofit property tax exemptions, setting out a wide-ranging agenda for research along multiple dimensions, including the impacts of nonprofit property tax exemptions, and the various ways in which such exemptions affect the behavior of nonprofit organizations. Research to date provides relatively little definitive understanding of impacts such as revenues foregone by local governments, changes in property values and tax burdens on homeowners, and influence on the size of the nonprofit sector and its market shares. Similarly, the effects of property tax exemption on many nonprofit organization decisions remain largely unresolved, including how nonprofits expend the savings from their exemptions (whether they increase or improve services, reduce prices or increase costs), where they locate, whether they choose to rent or own their facilities, and indeed whether social entrepreneurs are led to favor the nonprofit form when they engage in a 
social enterprise. All this is highly relevant to current policy deliberations in many states and localities centering on nonprofit property tax revocations and implementation of payments in lieu of taxes.

The economics research literature is richer in the area of government funding and tax policy towards nonprofits, especially at the federal level. Alm and Teles in Chapter 19 focus on state and federal tax policies, including the unrelated business income tax and tax incentives for charitable giving, while Toepler in Chapter 21 concentrates on direct governmental funding of nonprofits, each delineating what we have learned about the impacts of these policies and how they affect the management and behavior of the nonprofit organizations they influence. Alm and Teles review the state of research on corporate and personal income-tax incentives, especially at the federal level. Extensive research on the influence of the charitable deduction from personal federal income tax, specifically the tax price elasticity of giving, suggests that this deduction is efficient in raising charitable contributions in excess of government losses in tax receipts. However, much remains to be learned about how this effect varies by the specific target areas of charitable activity and by different segments of the donor population. Moreover, research on alternative ways in which tax incentives for giving could be structured, for example as credits rather than deductions, and at various levels and with limits and constraints on the amounts given and on the recipients of gifts, is fertile ground for future investigation. Here again, considerable progress has been made through experimental methods, but at times with mixed results. Even more fundamentally, Alm and Teles call for continued development of political economy theory to address the issue of why tax incentives are appropriate or desirable for raising charitable revenues to support public goods - focusing on the trade-off that governments face in sacrificing revenue to encourage philanthropy.

In this connection, Toepler in Chapter 21 examines the issues involved in direct government funding of nonprofit organizations. Conceptually, this topic may be seen as one manifestation of the contracting and outsourcing relationships considered by Alaimo in Chapter 12 and Tortia and Valentinov in Chapter 14. Here, however, Toepler examines the relationship mostly from the viewpoint of the contractee - in this case, nonprofit recipients of government support. (See also, Chapter 10 where Seaman cites the case of nonprofit humanitarian aid distributors using their 'buyer' power to influence the terms of obtaining vaccines from private for-profit suppliers, in contrast to governments as the 'seller'.) Toepler notes that there is a long history of scholarship on this deceptively complex topic, so it is no surprise that numerous negative and positive aspects of the government-nonprofit funding relationships have been identified and studied. On the positive side, government funding may allow nonprofits to scale up and to serve broader constituencies than they might otherwise, to professionalize their operations and possibly to achieve a greater degree of financial stability. On the negative side, government funding may create financial dependency and loss of autonomy, it may discourage independent policy advocacy, crowd out other sources of funds (see Chapter 2), permit mission drift, risk instability when government retrenches or alters its policies, and create cash flow and other problems stemming from faulty government management of purchase of service contracts. These various concerns suggest a rich future empirical research agenda, to investigate their veracity, impacts and implications. More broadly, Toepler raises the questions of 'How much dependency on government funding is too much?' and 'What "tools" of government funding of nonprofits in Salamon's (2002) terms, for example, 
contracts, grants, subsidies or tax incentives, work best for government to secure services from nonprofit organizations in different circumstances?'

Not all fertile areas of overlap between economics and management could be incorporated into this volume, though we have made progress since the first edition, especially by including discussion of the macroeconomy, an expanded international perspective, and more contributions from behavioral and experimental economics woven throughout diverse chapters. Economics, as the science of understanding how resources are deployed and utilized to produce social value, and which has sharp and probing analytical tools at its disposal, still has been only modestly applied to date to the critical management and policy questions affecting nonprofit organizations, and in turn to the contributions this sector makes to the overall welfare of our society. More than anything else, our authors have described a rich agenda of questions and topics that, if addressed by economists and organization and management and policy scholars at both the applied and theoretical levels, can further enhance the impact and value of economists' way of thinking, expand the domain of contributions of the economics profession, and add new sophistication and depth to the tools that nonprofit managers and leaders have at their disposal to effectively guide their organizations in an environment of perennially limited resources, volatility and institutional change.

\section{NOTES}

1. There are many contributions to these important methodological debates extending well beyond economics. A good overview of the issues regarding statistical versus economic significance is provided by Mayer (2013) and the further response to Mayer by Ziliak and McCloskey (2013). An excellent analysis and explanation for the relative absence of replication in economics is provided by Galiani et al. (2017), although again, the challenge of replicating results is hardly unique to economics.

2. The subfield of cultural economics, which includes but is not limited to the study of artists and nonprofit performing arts organizations, has also engaged in a lively debate as to whether a new kind of economics is required to understand the issues of valuation and behavior at least within that apparently unique sector of the economy (for example, Hutter and Throsby 2008). Indeed, economics has long recognized the limitation of price as a full measure of value, for example, its critical distinction between total value and marginal value in the famous water/diamond paradox.

\section{REFERENCES}

Galiani, Sebastian, Paul Gertler and Mauricio Romero (2017), 'Incentives for replication in economics', NBER Working Paper, National Bureau of Economic Research, 30 June.

Hutter, Michael and David Throsby (eds) (2008), Beyond Price. Value in Culture, Economics and the Arts, Cambridge: Cambridge University Press.

Mayer, Thomas (2013), 'Reply to Deidre McCloskey and Stephen Ziliak on statistical significance', Econ Journal Watch, 10 (1), 87-96.

Salamon, Lester M. (ed.) (2002), The Tools of Government: A Guide to the New Governance, New York: Oxford University Press.

Ziliak, Stephen T. and Deirdre N. McCloskey (2013), 'We agree that statistical significance proves essentially nothing: a rejoinder to Thomas Mayer', Econ Journal Watch, 10 (1), 97-106. 